\title{
Experimental Study of the Coal Slurry Dewatering
}

\author{
Valentin Kalashnikov ${ }^{1, *}$, Anton Gorbachev ${ }^{1}$, and Zuzana Šimková2 \\ ${ }^{1}$ JSC SUEK-Kuzbass, 652507 Leninsk-Kuznetskiy, Vasil'eva St., bld.1, Kemerovo region, Russia \\ ${ }^{2}$ Technical University of Košice, Faculty BERG, Park Komenského 19, 042 00, Košice, Slovakia
}

\begin{abstract}
Currently, over $50 \%$ of Russia's coal is mined in Kuzbass region. This is the reason for extreme pressure on natural resources and ecology in the region. At present, more than 100 coal mines and open-pit mines, as well as 54 concentrating plants and facilities are operating in Kuzbass. Wastewater and wastes of concentration plants, which used sludge collectors, contain significant amounts of coal slurry in the form of finely dispersed particles. Filtered cake as a potential raw material is of interest from an economic point of view. This technogenic raw material is a waste of mining production in fact. At the same time, the high humidity, and the complexity of loading and transportation, and the lack of compliance with consumer requirements does not allow full using of this raw material. This article presents some results of experimental research on coal sludge dewatering using geosynthetic materials. The received experimental data allow making the preliminary forecast about possibility of use of geotextilelike materials for coal slurry dewatering with its potential further use.
\end{abstract}

\section{Introduction}

The problem of mining waste utilization is caused by the economic and environmental component. Reducing the technogenic stress in Kuzbass through comprehensive exploitation of mineral resources with an increase in the waste-free component of technological processes will improve the complex environmental situation. This will be reflected in a reduction of surface and groundwater pollution, air and soil pollution, and a reduction in the land intensity of enterprises by reducing the area occupied by treatment facilities. In addition, the costs of enterprises will also be reduced by reducing environmental payments.

The main objectives of this study is the selection of the most optimal geotextile material (in terms of price/quality ratio) and technological scheme of dewatering of water-coal slurry formed in a radial thickener or available in slurry lagoons of the concentration plant in order to develop a low-cost technology of slurry dewatering.

\footnotetext{
* Corresponding author: kalashnikov suek@mail.ru
} 


\section{Materials and Methods}

In order to carry out experimental studies for collection, dewatering and preparation for transportation of coal slurry in the conditions of a coal concentration plant JSC "SUEKKuzbass", it was planned to perform the following types of works:

1) Preparation of the start experimental small size shell filtering constructions (SFC) from the different geotextile materials. As part of the ongoing study, materials are selected based on the lifetime of the SFC: prolonged outdoor storage is not foreseen, so such cost factors as increased resistance to UV radiation and external mechanical stress is not a necessary criteria for the choice of material [1,2]. Linear size of SFCs are $0.5 \times 0.5 \times 2$ meters. In our case the determining characteristics of the geotextile material will be its cost, filtering capacity in relation to water-coal slurry and the strength of the geotextile;

2) Placing of the SFC was carried out on the testing site in close proximity to the radial thickener of the concentrating plant [3-5]:

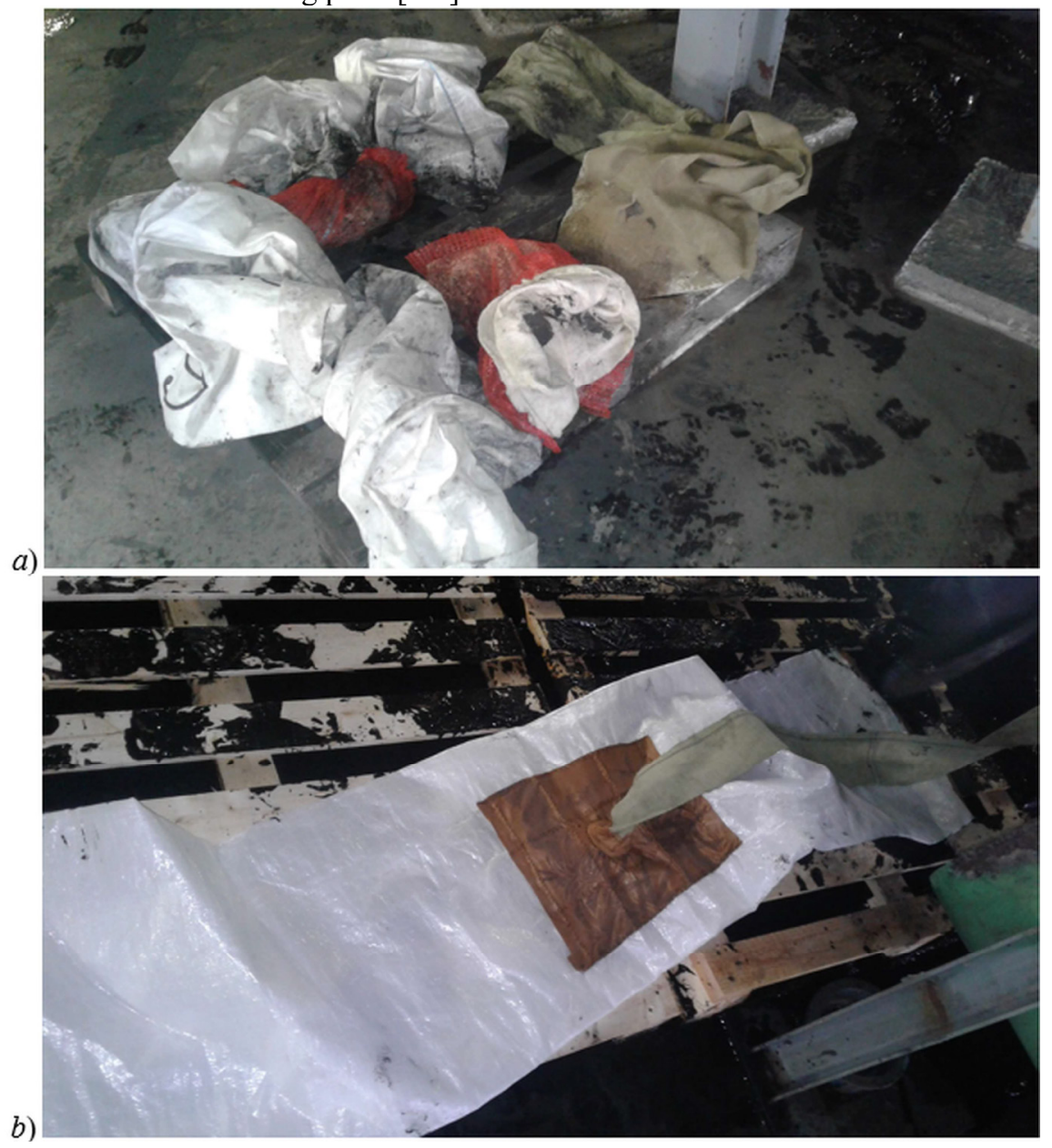

Fig. 1. The SFC prototypes placed on pallet: a) SFCs for manual filling, $b$ ) SFC for mechanized filling. SFC:

3)Sequential filling SFC by the water-coal slurry with sampling of slurry entering the 


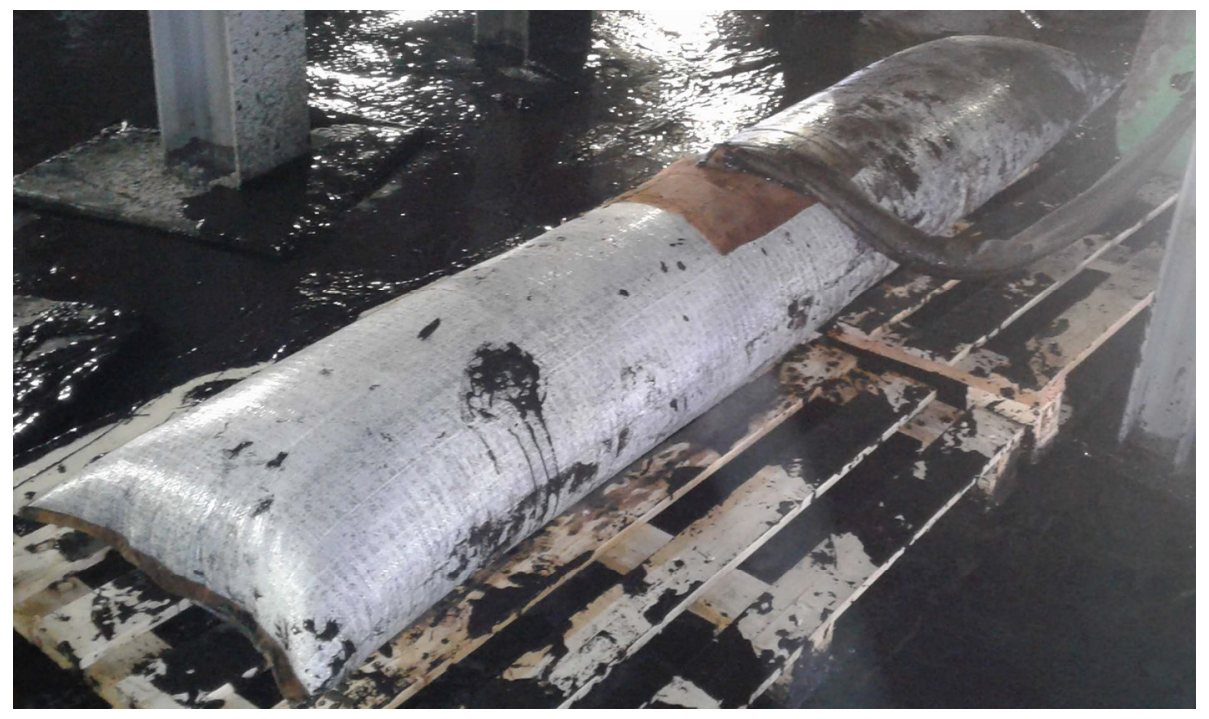

Fig. 2. The cylindrical SFC filled by water-coal slurry.

4) After the formation of the cake body inside the SFC it is assumed that the cake body's parts will be sampled to determine the moisture dynamics [6]. Sampling was carried out in accordance with Interstate Standart \#12071-2014 "Soils. Sampling, packing, transportation and storage of samples", i.e. by groove method with hermetic packing of samples for further laboratory tests;

5) The moisture of samples was determined in a laboratory in accordance with Interstate Standart \#5180-84 "Soils. Laboratory methods for determination of physical characteristics". The cake moisture $W$ is defined as the ratio of the mass of water removed from the cake by drying to the mass of the dried cake. For this purpose, a cake sample weighing 15-50 $\mathrm{g}$ is placed in a pre-dried, weighed bucket. After that, the sample of cake is weighed on the electronic scales ScoutPro SPS402F and dried in a drying oven for 3-5 hours at a temperature of $(105 \pm 2)^{\circ} \mathrm{C}$. After that the bucket is cooled in an desiccator with calcium chloride to room temperature and weighed [7-9]. Drying and cooling cycles are carried out up to the cake mass difference at sequential weighing not more than 0.02 gram.

Calculation of cake sample humidity is performed by formulae:

$$
W=\frac{m_{1}-m_{0}}{m_{0}-m} \cdot 100 \%
$$

where $W$ is the cake moisture, $\% ; m$ is the bucket mass, gram; $m_{l}$ is the mass of the bucket with wet cake, gram; $m_{l}$ is the mass of the bucket with dry cake, gram.

\section{Results and Discussion}

The main objectives of this study was the selection of the most optimal geotextile material (in terms of price/quality ratio).

The following starting prototypes of SFCs from geotextile-like and geotextile materials with capacity up to 50 litres each ones were produced for experimental tests:

1) polypropylene textile (cost $\$ 0.13$ per $\mathrm{m}^{2}$; density 83 gram per $\mathrm{m}^{2}$ );

2) tarpaulin (cost $\$ 2$ per $\mathrm{m}^{2}$; density 367 gram per $\mathrm{m}^{2}$ );

3) regular non-woven fabric (cost $\$ 0.5$ per $\mathrm{m}^{2}$; density 149 gram per $\left.\mathrm{m}^{2}\right)$;

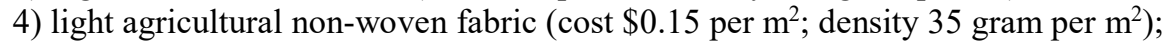

5) non-woven geotextile "Geotek 250" (cost $\$ 0.7$ per $\mathrm{m}^{2}$; density 230 gram per $\mathrm{m}^{2}$ ); 
6) non-woven geotextile "Geotek 350" (cost $\$ 1.1$ per $\mathrm{m}^{2}$; density 300 gram per $\mathrm{m}^{2}$ ).

The filling of the test SFCs under the radial thickener was done manually. Approximately 50 litres of water-coal slurry with an initial moisture content of $W=131.25 \%$ was placed in each SFC. Due to the low volume of filtrate released from the external side of the SFCs, no sampling such filtrate was carried out after SFCs filling. Approximately $0.4 \mathrm{~m}^{3}$ of water-coal slurry was injected into the cylindrical SFC by mechanical means.

After formation of the cake body inside the SFCs and its partial dewatering in 20 days and in 40 days after SFCs was filled with slurry cake samples were taken from cake body. Visually it was noted that the external part of the cake body directly adjacent to the surface of the SFC has lower humidity compared to the central part.

The results of the cake moisture study after 20 days and 40 days of exposure in various SFC are given in Table 1.

Table 1. The cake moisture for different exposure times.

\begin{tabular}{|l|c|c|}
\hline \multicolumn{1}{|c|}{ Geotextile material } & $\begin{array}{c}\text { Humidity } \boldsymbol{W}, \boldsymbol{\%}, \text { after } \\
\text { 20-day SFC exposure }\end{array}$ & $\begin{array}{c}\text { Humidity } \boldsymbol{W}, \boldsymbol{\%}, \text { after } \\
\text { 40-day SFC exposure }\end{array}$ \\
\hline polypropylene textile & 68.68 & 45.15 \\
\hline tarpaulin & 40.01 & 37.37 \\
\hline regular non-woven fabric & 56.93 & 48.19 \\
\hline agricultural non-woven fabric & 64.87 & 29.58 \\
\hline non-woven geotextile "Geotek 250" & 41.49 & 18.26 \\
\hline non-woven geotextile "Geotek 350" & 37.92 & 33.55 \\
\hline
\end{tabular}

Preliminary analysis of the obtained cake dewatering data has shown that the best quality materials (in terms of dewatering speed) are non-woven geotextiles "Geotek 250", "Geotek $350 "$, and tarpaulin $[10,11]$. At the same time, the cheapest materials are polypropylene fabric, regular non-woven fabric, and light agricultural non-woven fabric.

\section{Conclusions}

The collection and dewatering of coal slurry as raw material for further use with the help of SFCs is economically feasible for the following reasons:

- unification of the technological chain "collection and dewatering" of coal slurry from coal concentrating plants or mine waste water;

- optional use of flocculants in slurry to be dewatered;

- high rate of coal slurry dewatering in comparison with the sedimentation process in sludge lagoons;

- the SFC dewater of the slurry to the humidity $W \leq 20 \%$ or less $v s$ the press-filters product with higher humidity values ( $W \geq 40 \%$ );

- relatively low costs for the process dewatering;

- relatively small areas for SFCs placement and absence of special conditions for their placement (only the possibility of filtrate flow and loading of dried sludge into dump trucks is required);

- possibility of safe and quick disposal or reuse of the used SFCs. 


\section{References}

1. P.C. Lodi, B.S. Bueno, O.M. Vilar, N.S. Correia, Proceedings of the 4th Asian Regional Conference on Geosynthetics, June 17-20, 35-39 (2008)

2. L.D. Suits, Y.G. Hsuan, Geotextiles and Geomembranes, 21, 111 (2003)

3. V. Gusev, E. Maliukhina, International Journal of Applied Engineering Research, 11(11), 7238-7239 (2016)

4. E. Murko, V. Kalashnikov, A. Gorbachev, I. Mukhomedzyanov, E3S Web of Conferences, 105, 02029 (2019)

5. Y. Lesin, V. Gogolin, E. Murko, S. Markov, J. Kretschmann, E3S Web of Conferences, 41, 01039 (2018)

6. V. Murko, A. Zaostrovsky, E. Murko, M. Volkov, E3S Web of Conferences, 41, 01040 (2018)

7. M. Tyulenev, S. Markov, E. Makridin, Y. Lesin, V. Gogolin, E3S Web of Conferences, 105, 02022 (2019)

8. V.A. Kalashnikov, A.V. Gorbachev, J. of Mining and Geotechnical Engineering, 3, 56-79 (2018) DOI: 10.26730/2618-7434-2018-3-56-79

9. O.S. Misnikov, J. of Mining and Geotechnical Engineering, 2, 19-32 (2019) DOI: 10.26730/2618-7434-2019-2-19-32

10. O.O. Garshin, Z.A. Startseva, J. of Mining and Geotechnical Engineering, 2, 33-41 (2019) DOI: 10.26730/2618-7434-2019-2-33-41

11. V.A. Kalashnikov, A.V. Gorbachev, J. of Mining and Geotechnical Engineering, 3, 56-79 (2018) DOI: 10.26730/2618-7434-2018-3-56-79 